\title{
Fabrication of Acetaldehyde Gas Sensor through Nanostructured Iron Oxide Thin Films
}

\author{
Parthasarathy Srinivasan ${ }^{1}$, Arockia Jayalatha Kulandaisamy ${ }^{1}$, K. Jayanth Babu ${ }^{1}$, and John Bosco \\ Balaguru Rayappan ${ }^{1^{*}}$ \\ 1 Centre for Nanotechnology \& Advanced Biomaterials (CeNTAB) and \\ School of Electrical \& Electronics Engineering (SEEE) \\ SASTRA Deemed University, Thanjavur - 613 401, Tamil Nadu, India \\ Corresponding author's e-mail address: ribosco@ece.sastra.edu
}

\begin{abstract}
:
Acetaldehyde is one of the major biomarkers indicating the freshness levels of fruits and vegetables. In this context, we report the fabrication of room temperature acetaldehyde gas sensor using spray pyrolysis deposited iron oxide thin films. Influence of precursor concentrations (30, 50, 70 and 100 $\mathrm{mM}$ ) on the acetaldehyde sensing characteristics was investigated. Structural analysis of all the deposited thin films revealed the formation of orthorhombic phase iron oxide nanostructure with lattice parameters of $a=5.095 \AA b=8.789 \AA$ and $c=9.437 \AA$. Increased intensity of the preferential plane orientation (1 2 2) for $10 \mathrm{mM}$ precursor concentration revealed the enhanced crystallinity. Smaller spherical nanograins were observed for all the films and the film deposited at $50 \mathrm{mM}$ precursor concentration exhibited aggregated rod like features. The film deposited at $100 \mathrm{mM}$ precursor concentration showed excellent acetaldehyde sensing characteristics at room temperature with response-recovery times of $19 \mathrm{~s}$ and $25 \mathrm{~s}$ respectively.
\end{abstract}

Key words: Acetaldehyde sensor, iron oxide, thin film, spray pyrolysis, precursor concentration.

\section{References}

[1] A. Mirzaei, S.G. Leonardi, G. Neri, Detection of hazardous volatile organic compounds (VOCs) by metal oxide nanostructures-based gas sensors: A review, Ceram. Int. 42 (2016) 15119-15141. doi:10.1016/j.ceramint.2016.06.145.

[2] G.K. Mani, J.B.B. Rayappan, Novel and facile synthesis of randomly interconnected $\mathrm{ZnO}$ nanoplatelets using spray pyrolysis and their room temperature sensing characteristics, Sensors Actuators, B Chem. 198 (2014) 125133. doi:10.1016/j.snb.2014.02.101.

[3] C. Wang, L. Yin, L. Zhang, D. Xiang, R. Gao, Metal oxide gas sensors: Sensitivity and influencing factors, Sensors. 10 (2010) 20882106. doi:10.3390/s100302088.

[4] M.N. Huda, A. Walsh, Y.F. Yan, S.H. Wei, M.M. Al-Jassim, Electronic, structural, and magnetic effects of $3 d$ transition metals in hematite, J. $\begin{array}{lllll}\text { Appl. } & \text { Phys. } & 107 & \text { (2010) } & 123712 .\end{array}$ doi:10.1063/1.3432736

[5] M. Sassine, B. Picquet-Varrault, E. Perraudin, L. Chiappini, J.F. Doussin, C. George, A new device for formaldehyde and total aldehydes real-time monitoring, Environ. Sci. Pollut. Res. 21 (2014) 1258-1269. doi:10.1007/s11356-013-2010-5. 